\title{
Immunological studies in cystic fibrosis
}

\author{
M. W. TURNER, J. O. WARNER, C. R. STOKES,* AND A. P. NORMAN \\ From the Department of Immunology, Institute of Child Health, and the Respiratory Unit \\ The Hosyital for Sick Children, London
}

SUMMARY Evidence is presented to support the concept that much of the allergy in cystic fibrosis (CF) is IgE mediated. Total IgE levels were higher in allergic than in nonallergic CF patients. Levels were also higher in those patients who had had the greatest number of chest infections in the preceding 12 months. IgE antibody levels to Dermatophagoides pteronyssinus, Timothy grass pollen, and Aspergillus fumigatus were higher in those with positive results from skin tests to these allergens. The serum IgG, IgM, and IgA levels of allergic and nonallergic CF patients did not differ but the overall mean values for IgG and IgM were higher than those reported for healthy British children. The highest levels tended to be present in patients with the greatest number of recent major chest infections and the difference was significant for IgG. 16 patients had IgA levels $72 \mathrm{SD}$ below the reported means for age-matched controls and 11 of these were nonallergic. IgA levels were also higher in patients who had recently experienced major chest infections. 45 of the patients were tissue types for HLA A and B antigens but no significant clinical associations with single antigens were observed. The antigen phenotype A1 + B8 was more common in datients with multiple allergic symptoms than in those with a single allergy or merely a positive result from a skin test Nonsignificant increases of W19 in patients with frequent infections and of A2 in patients presenting with meconium ileus were also noted. The data presented do not permit a choice to be made between the alternative concepts of allergy as a primary abnormality in CF, and allergy arising secondary to infection.

There is an increased incidence of immediate skin hypersensitivity to various inhalent allergens, particularly moulds, in patients with cystic fibrosis (CF) (Mearns et al., 1967; Allan et al., 1975; Warren et al., 1975; Warner et al., 1976b). Warner et al. $(1976 \mathrm{a}, \mathrm{b})$ suggested that the allergy arises as a result of defective allergen elimination at mucosal surfaces, because of abnormal mucociliary clearance in the respiratory tract, either secondary to infection or as a primary abnormality in CF. We report here the results of several immunological investigations and their relationships to allergy and recent chest infections in a large group of children with CF.

\section{Patients and methods}

Children with CF (sweat $\mathrm{Na}>70 \mathrm{mEq} / \mathrm{l}$ ) attending the CF outpatient clinic at this hospital were studied. The patients were included in the study sequentially as they attended the clinic and no

Recejved 19 December 1977

*Present address: Department of Animal Husbandry, University of Bristol attempt was made to be selective. Their ages ranged from 4 months to 18 years and none had serious or acute infection at the time of testing, although the extent of their chest disease ranged from very severe to slight. The number of major chest infections in the 12 months preceding the study was recorded. A major infection was one that required being in hospital and at least three of the following criteria being present: fever, increased cough with purulent sputum, breathlessness, and increased lung shadowing on $x$-ray. Prick skin testing was done on the forearms or back using 12 Bencard skin test antigens (house dust extract (150\%), Dermatophagoides pteronyssinus $(1 \cdot 2 \%)$ and Dermatophagoides farinae $(1 \cdot 2 \%)$, feathers $(150 \%)$, cat fur $(150 \%)$, dog hair $(150 \%)$, whole egg $(6 \%)$, milk ( $10 \%)$, Timothy grass $(2.5 \%)$, rye grass $(2.5 \%)$, Aspergillus fumigatus $(5 \%)$, and Cladosporium (10\%)) and a control solution. Reactions were examined between 15 and 20 minutes later and considered positive if there was a weal of $3 \mathrm{~mm}$ diameter or greater.

No patient reacted to the control solution. Blood samples were obtained at the time of skin testing and serum was stored at $-70^{\circ} \mathrm{C}$ until required. 
Serum IgE was measured by a modification of the double antibody procedure (Nye et al., 1975) using rabbit antihuman IgE (Hoechst Pharmaceuticals, England) in the first stage and donkey antirabbit serum (Wellcome Reagents Ltd) in the second stage; results were expressed as international units per $\mathrm{ml}$ using a commercial standard (Pharmacia) calibrated against the WHO IgE standard 58/341. The threshold of detectability in this assay was $4 \mathrm{IU} / \mathrm{ml}$.

IgE antibodies were assayed by a modification of the procedure of Wide $e t$ al. (1967). Extracts of $D$. pteronyssinus. Timothy grass pollen, and $A$. fumigatus (Bencard) were coupled to cyanogen-bromide activated microcrystalline cellulose particles (Sigma). $0.5 \mathrm{ml}$ of a $1 \mathrm{mg} / \mathrm{ml}$ suspension of cellulose particles with bound antigen was mixed with $50 \mu l$ serum and incubated at room temperature for 16 hours with continuous mixing. The cellulose particles were then washed 6 times with physiological saline containing $1 \%$ Tween-20 and $100 \mu l$ of ${ }^{125}$ I-labelled specific rabbit antihuman IgE (Fc-immunosorbent purified) added. After overnight incubation with agitation at room temperature, the supernatants were removed and the particles washed 5 times with physiological saline containing $1 \%$ Tween-20. Radioactivity was counted in a $\gamma$ counter and results expressed as a percentage of the total radioactive counts which became bound. All sera were analysed in a single batch and positive and negative controls were included.

Serum IgG, IgA, and IgM levels were measured by the single radial diffusion method (Fahey and McKelvey, 1965) using antisera supplied by Wellcome Reagents Ltd. A WHO reference standard for immunoglobulins (67/99) was used throughout and results expressed in $\mathrm{IU} / \mathrm{ml}$.

HLA tissue typing was done by the microcytotoxicity method (Mittal et al., 1968) on patients' lymphocytes separated on a Ficoll-Triosil density gradient. Eight antigens of the $A$ series and 14 antigens of the B series were tested using 108 antisera kindly provided by the National Organ Matching and Distribution Service, Bristol.

Differences in IgE antibody and total IgE, IgG, and IgM levels were analysed by Student's $t$ test on log-transformed data. The frequencies of individual HLA antigens and certain antigen combinations were analysed by $\chi^{2}$ tests (with Yates's correction) or by Fisher's exact test.

\section{Results}

IgE levels. The IgE levels of 103 patients with CF plotted according to age are shown in Fig. 1. With the assay used, the nonatopic adult mean value is $17 \mathrm{IU} / \mathrm{ml}(2 \mathrm{SD}$, range $<2-195)$ and peak values are

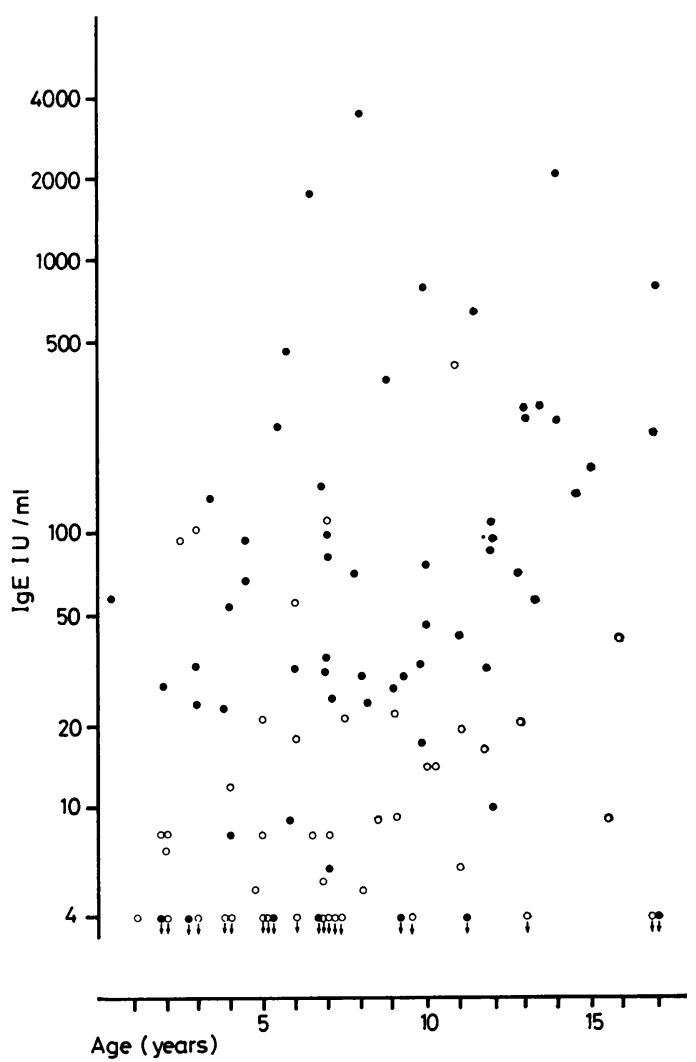

$O=$ patients who were skin test negative to all allergens; $O=$ patients with one or more positive skin tests.

Fig. 1 Serum IgE levels of patients with $C F$.

reached by approximately 5 years of age (unpublished observations). Patients were classified as allergic if one or more skin test gave positive results. Children who were allergic and at least 4 years old had a significantly higher mean IgE $(75 \mathrm{IU} / \mathrm{ml})$ than nonallergic children of the same age $(10 \mathrm{IU} / \mathrm{ml})(t=5 \cdot 69$; $P<0 \cdot 001)$. The percentage of children with a total IgE $>20 \mathrm{IU} / \mathrm{ml}$ increased from $43 \%$ in the 5 - to 10 -year-old group to $66 \%$ in those children older than 10 years, but this was not significant.

The relationship between IgE level and recent chest infections was studied in children over the age of 5 years. Patients were grouped according to the number of major chest infections in the preceding 12 months (group 1, no infections; group 2, 1 infection; group 3,2-4 infections; group 4,>4 infections). Fig. 2 shows the mean IgE level of patients in each of these groups and Table 1 gives the $t$ test comparisons for the four groups and for patients with no infections (group 1) compared with patients having 


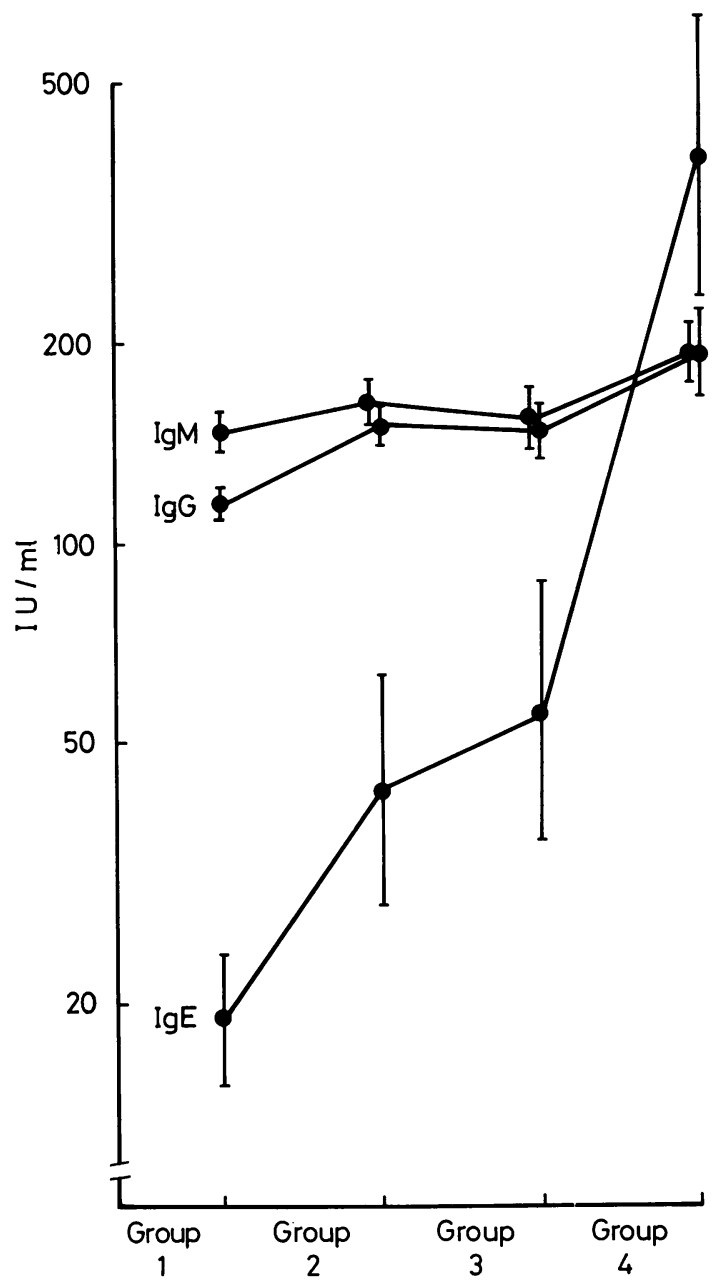

Group $1=0$ infections; group $2=1$ infection; group $3=2$ to 4 infections; group $4=>4$ infections. Each vertical bar represents the s.e. mean.

Fig. 2 Mean $\operatorname{IgE}, \operatorname{IgG}$, and IgM levels of patients with $C F$, classified according to the number of major chest infections in the preceding 12 months. IgE data for patients aged 5 years and above; IgG and IgM data for patients aged 2 years and above. infections. IgE levels are clearly related to the number of recent infective episodes.

IgE antibodies. The levels of IgE antibodies to $D$. pteronyssinus, Timothy grass pollen, and $A$. fumigatus are plotted in Fig. 3. For all three allergens IgE antibody levels were significantly different between those patients who gave positive results and those who gave negative results to the skin test ( $D$. pteronyssinus, $t=7.95, \mathrm{P}<0.001$; Timothy grass pollen, $t=6 \cdot 66, \mathrm{P}<0.001 ; A$. fumigatus, $t=5 \cdot 97$, $\mathrm{P}<0.001$ ). This is consistent with the view that the patient's allergy is, at least partly, IgE mediated.

IgG, IgA, and IgM levels. The total serum IgG, IgA, and IgM levels in 106 patients with CF are plotted according to age in Fig. 4. The mean serum IgG and IgM levels for CF patients older than 2 years were $131 \mathrm{IU} / \mathrm{ml}$ and $162 \mathrm{IU} / \mathrm{ml}$ respectively, both higher than the mean values reported by Hobbs (1970) for healthy British children (87 IU/ml and $106 \mathrm{IU} / \mathrm{ml}$ respectively). Some of the children below the age of 2 years had surprisingly low levels of IgG and IgM.

There was no significant difference between serum IgG and IgM levels in allergic and nonallergic CF children but a relationship between level and the number of recent infections was noted (Fig. 2 and Table 1). However, whereas children with no infections had significantly lower IgG levels than those who had had one or more infections, there was no significant difference between the IgM levels in the groups of patients.

As IgA levels rise progressively with age, analysis of the data is more difficult. Overall, there was no obvious difference in the $\operatorname{IgA}$ level of allergic and nonallergic CF children. A surprising number of children had rather low levels of IgA. 16 were more than 2 SD below the mean reported for healthy British children (Hobbs, 1970) and 11 of these were nonallergic, a significantly higher proportion than in the rest of the CF children $\left(\chi^{2}=4 \cdot 3 ; P<0 \cdot 05\right)$. In 3 of the 16 patients IgA was not detected $(<4 \mathrm{IU} / \mathrm{ml})$.

Table 1 Student's $t$ test comparisons of immunoglobulin concentrations in CF patients (grouped according to the number of major chest infections in the preceding 12 months*).

\begin{tabular}{|c|c|c|c|c|c|c|c|c|c|}
\hline & \multicolumn{3}{|c|}{$I g E$} & \multicolumn{3}{|l|}{$I g G$} & \multicolumn{3}{|c|}{$I g M$} \\
\hline & $n$ & $t$ & $\mathbf{P}$ & $n$ & $t$ & $\mathbf{P}$ & $n$ & $t$ & $\mathbf{P}$ \\
\hline $\begin{aligned} \text { *Group } 1 \text { v. } 2 \\
1 \text { v. } 3 \\
1 \text { v. } 4 \\
2 \text { v. } 3 \\
2 \text { v. } 4 \\
3 \text { v. } 4 \\
1 \text { v. } 2+3+4\end{aligned}$ & $\begin{array}{l}60 \\
51 \\
53 \\
27 \\
29 \\
20 \\
82\end{array}$ & $\begin{array}{l}1 \cdot 8558 \\
2 \cdot 0545 \\
5.9630 \\
0.4342 \\
3 \cdot 5303 \\
2 \cdot 8793 \\
4 \cdot 0968\end{array}$ & $\begin{array}{l}\text { NS } \\
<0.05 \\
<0.001 \\
\text { NS } \\
<0.005 \\
<0.01 \\
<0.001\end{array}$ & $\begin{array}{r}75 \\
70 \\
68 \\
31 \\
29 \\
24 \\
101\end{array}$ & $\begin{array}{l}3 \cdot 0334 \\
2 \cdot 3447 \\
4 \cdot 2242 \\
0 \cdot 2465 \\
1 \cdot 7448 \\
1 \cdot 6385 \\
4 \cdot 5537\end{array}$ & $\begin{array}{l}<0.005 \\
<0.025 \\
<0.001 \\
\text { NS } \\
\text { NS } \\
\text { NS } \\
<0.001\end{array}$ & $\begin{array}{r}76 \\
71 \\
69 \\
31 \\
29 \\
24 \\
102\end{array}$ & $\begin{array}{l}0.7195 \\
0 \cdot 2631 \\
1.6756 \\
0.4112 \\
1 \cdot 3273 \\
1.5210 \\
1 \cdot 3330\end{array}$ & $\begin{array}{l}\text { NS } \\
\text { NS } \\
\text { NS } \\
\text { NS } \\
\text { NS } \\
\text { NS } \\
\text { NS }\end{array}$ \\
\hline
\end{tabular}

*Group $1=0$ infections, group $2=1$ infection, group $3=2-4$ infections, group $4=>4$ infections. 


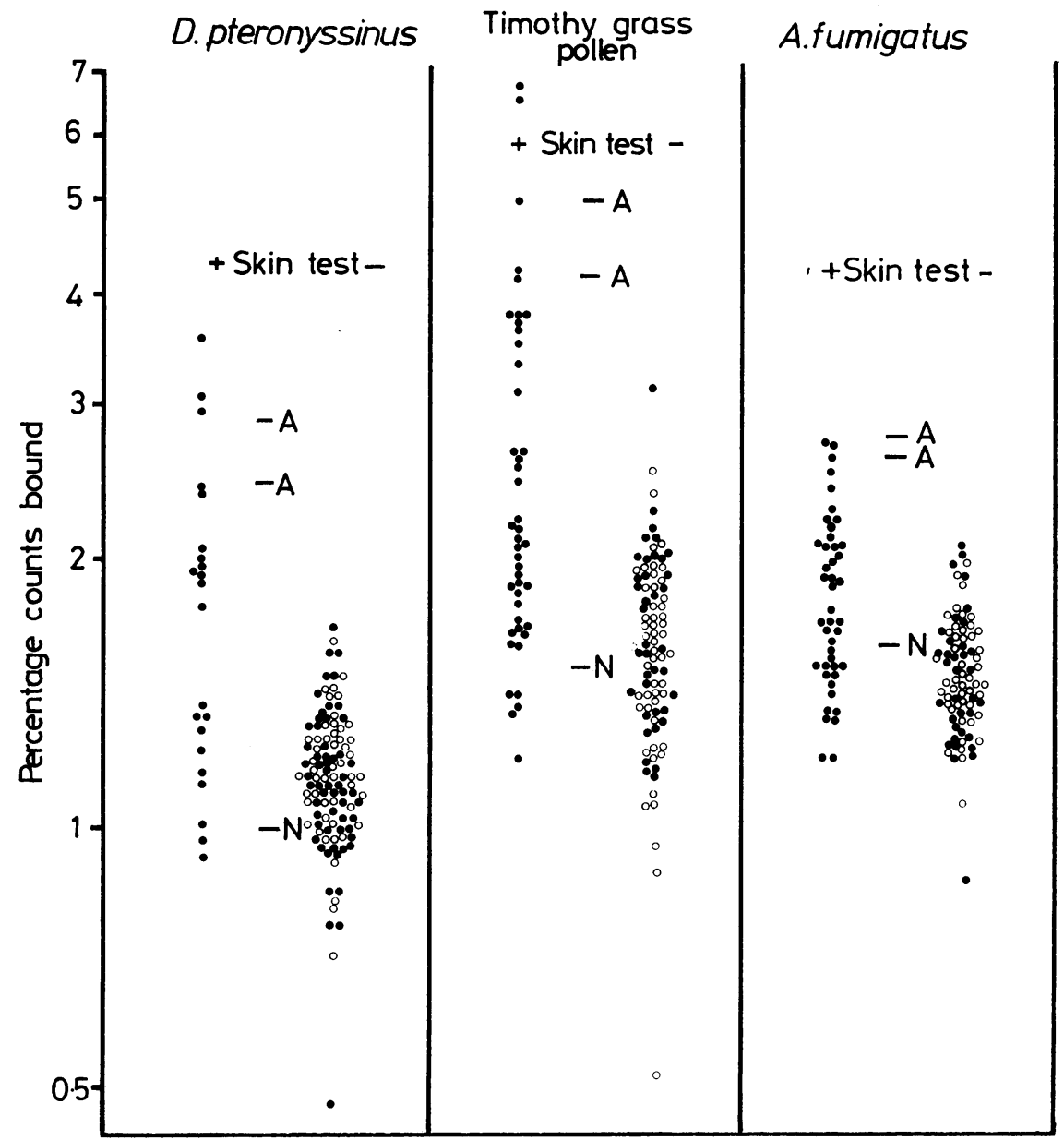

in a skin test negative column indicates an individual with one or more positive skin tests to other allergens; $O$ individuals who were skin test negative to allallergens. For each allergen the binding observed for two skin test positive (non CF) individuals is indicated (A) as well as a skin test negative control value (N).

Fig. 3 Levels of serum IgE binding to immunosorbents of D. pteronyssinus, Timothy grass pollen, and A. fumigatus (\% counts bound) in patients with $C F$, classified as skin test positive or negative for each allergen.

The relationship between IgA level and number of recent chest infections was studied by comparing the number of patients with serum $\operatorname{IgA}$ levels above and below the published age-related mean values for healthy British children Hobbs, (1970). These data, presented in Table 2, show that IgA levels are also significantly related to the number of recent infective episodes.

HLA typing. The frequencies of the HLA A and B antigens in 45 of the children with CF are presented in Table 3. The antigens $\mathrm{W} 19, \mathrm{~B} 5$, and B12 were detected more often in the patients than in a control
Table 2 Numbers of patients with $C F$ with serum Ig $A$ levels above and below age-related British mean values (Hobbs, 1970). (Patients grouped according to the number of infections in the preceeding 12 months.)

\begin{tabular}{|c|c|c|c|c|}
\hline Group* & $\begin{array}{l}\text { Above } \\
\text { mean }\end{array}$ & $\begin{array}{l}\text { Below } \\
\text { mean }\end{array}$ & Fisher's exact test & $\chi^{2}$ test \\
\hline $\begin{array}{l}1 \\
2 \\
3 \\
4 \\
2,3, \& 4\end{array}$ & $\begin{array}{r}20 \\
13 \\
8 \\
11 \\
32\end{array}$ & $\begin{array}{r}39 \\
5 \\
8 \\
1 \\
14\end{array}$ & $\begin{array}{l}P<0.01 \\
P \vee 0.025\end{array}$ & $P<0.001$ \\
\hline
\end{tabular}

*See classifications of groups in footnote to Table 1. 


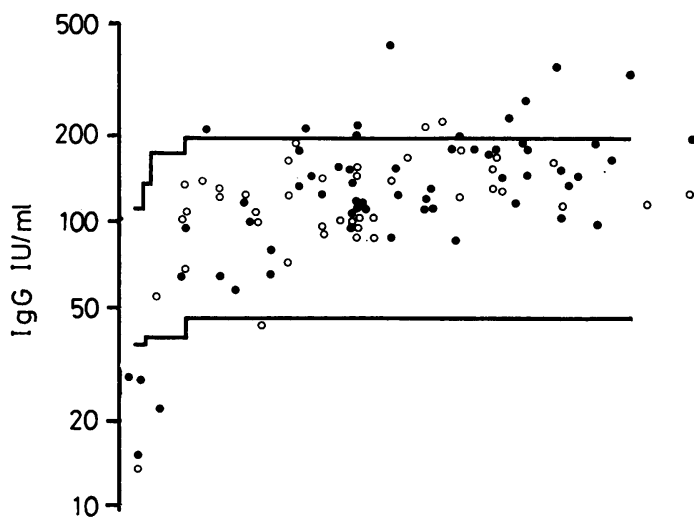

Table 3 Frequency of HLA tissue types in 45 patients with $C F$

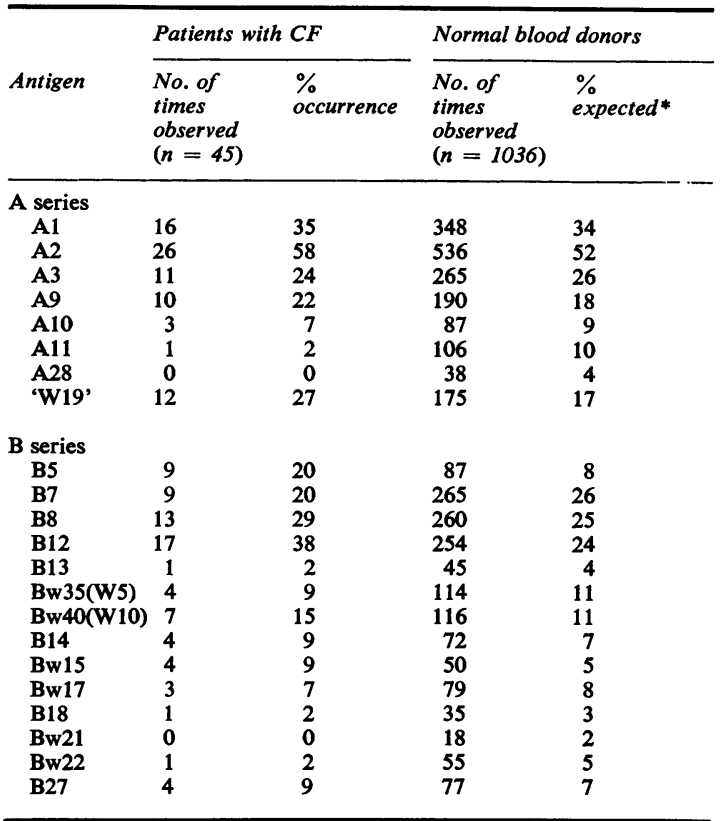

*Nelson et al. (1974).

population but the differences were not significant after correction for the number of antigen comparisons. This correction is used because in typing a group of patients for 20 different HLA antigens a spurious association with one of the 20 is likely to be significant at the $5 \%$ level (Svejgaard et al., 1975). Similarly, the frequencies of the three common HLA phenotypes A1 +B8 (24\%), A2+B12 (24\%), and A3 +B7 (13\%) did not differ significantly from the frequencies of these antigens in the normal population (G. H. Tovey, 1976, personal communication).

The children with CF had the full range of allergic symptoms (Warner et al., 1976b) and as the HLA phenotypes $\mathbf{A} 1+B 8$ and $A 3+B 7$ are associated with different allergic manifestations in patients without CF (Turner et al., 1977), we examined these antigen combinations in the 28 CF patients who gave a positive skin test result to one or more allergens. Of the 18 allergic patients with a single clinical symptom only 2 had the A1 + B8 combination and 3 had $\mathrm{A} 3+\mathrm{B} 27$. Of the 10 allergic patients with two or more clinical symptoms, 4 had the A1 +B8 combinaAge (years) tion and none was typed positive for $\mathrm{A} 3+\mathrm{B} 27$ (Fig. 5). These differences are not statistically significant in this small series but the trend is similar to that seen in our earlier study of non CF patients (Turner et al., 1977).

Fig. 4 Serum $\operatorname{IgG}, \operatorname{IgA}$, and IgM levels of patients with $C F$. 


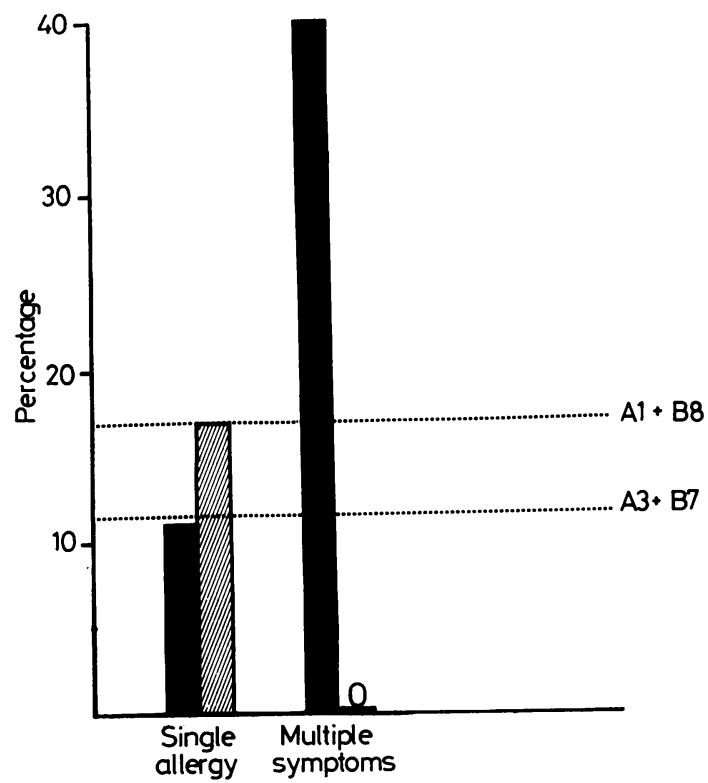

Fig. 5 Frequencies of the $H L A$ antigen combinations $A 1+B 8$ (solid column) and $A 3+B 7$ (hatched column) in 18 CF patients with a single allergy (one allergic symptom and/or positive skin test) and $10 \mathrm{CF}$ patients with two or more clinical symptoms of allergy. The incidence in a general population for these antigens is indicated by the horizontal lines.

The relationship between tissue type and recent chest infections was studied using the four groups described above. No significant associations were noted but there was a trend for W19 to be increased in those with the most infections. This antigen was present in 4 of the 6 individuals who had $>4$ infections but in only 8 of 35 individuals with fewer than 4 infections in the previous 12 months. Similarly W19 was observed in 8 of the 19 patients with recent infections but in only 4 of the 22 with no chest infections.

Patients were also classified according to presentation with or without meconium ileus and the tissue types of these two groups compared. The antigen A2 was present in 9 of 11 patients presenting with meconium ileus compared with 15 of 30 without. This trend was not significant by Fisher's exact test.

\section{Discussion}

We have previously reported on the incidence of allergy in this CF population (Warner et al., 1976b). Unlike most atopic individuals CF homozygotes often have a large number of positive skin test reactions to the moulds $A$. fumigatus and $C$. herbarum (Mearns et al., 1967; Warner et al., 1976b).
Nevertheless, our combined IgE and IgE antibody results suggest that much of this allergy is reaginic (Type 1 immediate hypersensitivity (Coombs and Gell, 1975).

In a study of 40 patients with CF, Wallwork et al. (1974) also noted elevated IgE levels but Weeke et al. (1976), using the same radioimmunosorbent technique (RIST), found 'normal' IgE levels in 30 of $32 \mathrm{CF}$ patients. These apparent discrepancies are probably due to the relative insensitivity of the original RIST technique at levels of IgE below 100 $\mathrm{IU} / \mathrm{ml}$. Using the double antibody procedure we found clear differences (even below $100 \mathrm{IU} / \mathrm{ml}$ ) in the IgE levels between allergic and nonallergic CF patients.

In a study of $35 \mathrm{CF}$ patients Warren et al. (1975) reported elevated IgE antibodies to D.pteronyssinus in 3 of 5 patients with positive results to prick skin tests with this antigen. Similarly, elevated IgE antibodies to grass pollen and $A$. fumigatus were found in 7 of 9 and in 15 of 21 patients, respectively, with positive results to prick skin tests to these antigens. We have confirmed these associations in our larger series of 106 patients.

IgG anaphylactic antibodies have been implicated in some types of immediate hypersensitivity (Parish, 1970), and Shakib et al. (1976) have claimed that IgG4 levels were selectively elevated in 8 out of 18 patients with CF. The authors suggested that this might be significant in view of the observations of Stanworth and Smith (1973) that IgG4 myeloma proteins can block baboon PCA reactions mediated by IgE reaginic antibodies. However, Shakib et al. (1976) also found an elevation of IgG1 in 5 of 18 patients and that, in general, those with high IgG4 levels had evidence of recent infections. We have not investigated a possible anaphylactic role for IgG antibodies in the allergy of CF patients but in our series high levels of IgG were associated with frequent infection but not necessarily allergy. Before IgG4 reaginic antibodies can be implicated in CF, subclass specific antibody studies with appropriate allergen preparations will be required.

IgA was not detected in 3 of 106 patients, a much higher incidence than that reported for the general population (1 in 500, Lancet, 1975). In view of the association between transient IgA deficiency and allergy (Taylor et al., 1973; Soothill et al., 1976), it is surprising that most of our patients with CF and low levels of $\operatorname{IgA}$ were not allergic.

There is evidence that allergic CF patients have worse chest disease, a greater degree of bronchial lability, and are more likely to respond favourably to bronchodilators than are nonallergic CF patients (J. F. Price et al., 1978, unpublished). In the present study IgG, IgA, and IgE levels were significantly 
higher in the CF patients with several recent chest infections. A similar trend was noted for IgM but this was not significant. Wallwork et al. (1974), Warren $e t$ al. (1975), and Weeke et al. (1976) have also reported raised levels of IgG and IgA in smaller groups of CF patients but none of these authors has analysed data in terms of recent episodes of infection.

Our failure to observe any abnormal frequency of HLA antigens in patients with CF is in agreement with another study of 24 patients (Polymenidis et al., 1973) but it differs from a recent report (Kaiser et al., 1976 ) in which the antigen B18 was said to be more common in both patients and heterozygotes. However, the numbers studied were small (12 patients and 32 heterozygotes) and only the patients differ significantly from the normal frequency if a correction for the number of antigen comparisons is made (Svejgaard et al., 1975). In our previous study of HLA antigens in various groups of allergic individuals (Turner et al., 1977) we found an increased incidence of the antigen combination $\mathrm{A} 1+\mathrm{B} 8$ in patients who had presented with eczema and subsequently developed other allergic diseases. Patients with a single allergic disease did not show such an increase although the A1: B8 haplotype is known to be associated with many other nonallergic diseases-coeliac disease (McNeish et al., 1973), dermatitis herpetiformis (Gebhard et al., 1973), chronic active hepatitis (Mackay and Morris, 1972), and myasthenia gravis (Pirskanen et al., 1972), as well as with a high graft rejection rate in recipients of parental kidney grafts (Mickey et al., 1971). This has led to the suggestion that individuals with these antigens have a hyper-reactive immune response. Our observations that $\mathbf{A} 1+\mathbf{B} 8$ occurs more often in CF patients with multisystem allergic disease than in CF patients with a single disease symptom is in agreement with our earlier findings and could be explained by such a hyper-reactive mechanism. The nonsignificant associations between W19 and recent infections, and $\mathrm{A} 2$ and meconium ileus are of interest but require confirmation in a larger series.

The data obtained in this study extend our knowledge of the immunological changes characteristic of $\mathrm{CF}$ and highlight the close association between recent infections and serum levels of the immunoglobulins, including IgE. Whether the high incidence of allergy in CF reflects IgE sensitisation secondary to infections with adjuventising organisms or arises through some unknown mechanism related to the underlying defect remains to be determined. We found no evidence to suggest linkage of the CF gene to the HLA complex and the strongest association observed (between $\mathbf{A} 1+\mathbf{B 8}$ and multiple allergic symptoms) is also commonly found in nonCF atopics.
We thank Miss Antoinette Skelton and Mr J. O'Shea for technical assistance. The Joint Research Board of this hospital and institute, and the Chest and Heart Association gave essential financial support.

\section{References}

Allan, J. D., Moss, A. D., Wallwork, J. C., and McFarlane, H. (1975). Immediate hypersensitivity in patients with cystic fibrosis. Clinical Allergy, 5, 255-261.

Coombs, R. R. A., and Gell, P. G. H. (1975). Classification of allergic reactions responsible for clinical hypersensitivity and disease. In Clinical Aspects of Immunology, third edition, pp. 761-781. Edited by P. G. H. Gell, R. R. A. Coombs, and P. J. Lachmann. Blackwell: Oxford.

Fahey, J. L., and McKelvey, E. M. (1965). Quantitative determination of serum immunoglobulins in antibodyagar plates. Journal of Immunology, 94, 84-90.

Gebhard, R. L., Katz, S. I., Marks, J., Shuster, S., Trapani, R. J., Rogentine, G. N., and Strober, W. (1973). HL-A antigen type and small-intestinal disease in dermatitis herpetiformis. Lancet, 2, 760-762.

Hobbs, J. R. (1970). Simplified radial immunodiffusion. Association of Clinical Pathologists Broadsheet No. 68, pp. 1-8.

Kaiser, G. I., Laszlo, A., and Gyurkovits, K., editors (1976). HLA antigens in cystic fibrosis; an association of B18 with the disease. In $H L A$ and Disease, p. 252 (abstracts). INSERM: Paris.

Lancet (1975). Leading article: Selective IgA deficiency. Lancet, 2, 1291-1292.

Mackay, I. R., and Morris, P. J. (1972). Association of autoimmune active chronic hepatitis with HL-A1,8. Lancet, 2 , 793-795.

McNeish, A. S., Nelson, R., and Mackintosh, P. (1973). HL-A1 and 8 in childhood coeliac disease. Lancet, 1, 668.

Mearns, M., Longbottom, J., and Batten, J. (1967). Precipitating antibodies to Aspergillus fumigatus in cystic fibrosis. Lancet, 1, 538-539.

Mickey, M. R., Kreisler, M., Albert, E. D., Tanaka, N., and Terasaki, P. I. (1971). Analysis of HL-A incompatibility in human renal transplants. Tissue Antigens, 1, 57-67.

Mittal, K. K., Mickey, M. R., Singal, D. P., and Terasaki, P. I. (1968). Serotyping for homotransplantation. XVIII. Refinement of microdroplet lymphocyte cytotoxicity test. Transplantation, 6, 913-927.

Nelson, S. D., Darke, C., and Tovey, G. H. (1974). HL-A antigen frequencies in normal blood donors, kidney donors, and prospective kidney recipients. Tissue Antigens, 4, 361-365.

Nye, L., Merrett, T. G., Landon, J., and White, R. J. (1975). A detailed investigation of circulating IgE levels in a normal population. Clinical Allergy, 5, 13-24.

Parish, W. E. (1970). Short-term anaphylactic IgG antibodies in human sera. Lancet, 2, 591-592.

Pirskanen, R., Tiilikainen, A., and Hokkanen, E. (1972). Histocompatibility (HL-A) antigens associated with myasthenia gravis. Annals of Clinical Research, 4, 304-306.

Polymenidis, Z., Ludwig, H., and Götz, M. (1973). Cystic fibrosis and HL-A antigens. Lancet, 2, 1452.

Shakib, F., Stanworth, D. R., Smalley, C. A., and Brown G. A. (1976). Elevated serum IgG4 levels in cystic fibrosis patients. Clinical Allergy, 6, 237-240.

Soothill, J. F., Stokes, C. R., Turner, M. W., Norman, A. P., and Taylor, B. (1976). Predisposing factors and the development of reaginic allergy in infancy. Clinical Allergy, 6, 305-319. 
Stanworth, D. R., and Smith, A. K. (1973). Inhibition of reagin-mediated PCA reactions in baboons by the human IgG4 subclass. Clinical Allergy, 3, 37-41.

Svejgaard, A., Platz, P., Ryder, L. P., Nielsen, L. S., and Thomson, M. (1975). HL-A and disease associations-a survey. Transplantation Reviews, 22, 3-43.

Taylor, B., Norman, A. P., Orgel, H. A., Stokes, C. R., Turner, M. W., and Soothill, J. F. (1973). Transient IgA deficiency in pathogenisis of infantile atopy. Lancet, 2, 111-113.

Turner, M. W., Brostoff, J., Wells, R. S., Stokes, C. R., and Soothill, J. F. (1977). HLA in eczema and hayfever. Clinical and Experimental Immunology, 27, 43-47.

Wallwork, J. C., Brenchley, P., McCarthy, J., Allan, J. D., Moss, D., Milford Ward, A., Holzel, A., Williams, R. F., and McFarlane, H. (1974). Some aspects of immunity in patients with cystic fibrosis. Clinical and Experimental Immunology, 18, 303-320.

Warner, J. O., Norman, A. P., and Soothill, J. F. (1976a). Cystic fibrosis heterozygosity in the pathogenesis of allergy. Lancet, 1, 990-991.
Warner, J. O., Taylor, B. W., Norman, A. P., and Soothill, J. F. (1976b). Association of cystic fibrosis with allergy. Archives of Disease in Childhood, 51, 507-511.

Warren, C. P. W., Tai, E., Batten, J. C., Hutchcroft, B. J., and Pepys, J. (1975). Cystic fibrosis-immunological reactions to $A$. fumigatus and common allergens. Clinical Allergy, 5, 1-12.

Weeke, B., Flensborg, E. W., Jacobsen, L., Jørgensen, B. A., Lykkegaard, E., and Høiby, N. (1976). Immunochemical quantitation of 18 proteins in sera from patients with cystic fibrosis: concentrations correlated to class of fibroblast metachromasia, clinical and radiological lung symptoms. Danish Medical Bulletin, 23, 155-160.

Wide, L., Bennich, H. H., and Johansson, S. G. O. (1967). Diagnosis of allergy by an in vitro test for allergen antibodies. Lancet, 2, 1105-1107.

Correspondence to Dr M. W. Turner, Institute of Child Health, Department of Immunology, 30 Guilford Street, London WC1N 1EH. 